\title{
The Acquisition and Use of the -S Plural Morpheme by Third-Year Students of English in a Nigerian University
}

\author{
Roseline Abonego Adejare \\ Department of Language, Arts and Social Science Education, Lagos State University, Ojo, Nigeria \\ Email: abonego@yahoo.com
}

How to cite this paper: Adejare, R. A. (2019). The Acquisition and Use of the -S Plural Morpheme by Third-Year Students of English in a Nigerian University. Open Journal of Modern Linguistics, 9, 416-445. https://doi.org/10.4236/ojml.2019.96034

Received: October 4, 2019

Accepted: November 10, 2019

Published: November 13, 2019

Copyright $\odot 2019$ by author(s) and Scientific Research Publishing Inc. This work is licensed under the Creative Commons Attribution International License (CC BY 4.0).

http://creativecommons.org/licenses/by/4.0/

\begin{abstract}
This study examined the acquisition and use of the -S plural morpheme by third-year English undergraduates neglected in previous studies involving advanced L2 learners. It aimed at identifying all accurate and inaccurate instantiations of the form, determining their frequency of occurrence, specifying the context of occurrence of each plural bearing or non-bearing common noun, accounting for errors, and suggesting ways of improving L2 learners' acquisition and use of the English -S plural morpheme. The data comprised 1219 common nouns generated from essays written by 15 volunteer English Education students at the Lagos State University, Nigeria. The Combined CA-EA-IL theory which argues that neither CA nor EA nor IL is sufficiently powerful on its own to account for L2 acquisition guided the study, while syntactic and textual parameters aided the analysis. Findings showed that 93 percent (1132) of the data represent correct usage and 7.14 percent (87) represent incorrect usage. Non-suppliance of the $-S$ plural morpheme in nonobligatory contexts accounted for 74.2 percent (905), while its suppliance in obligatory contexts, non-suppliance in obligatory contexts, and suppliance in non-obligatory contexts respectively represent 18.6 (227), 6.1 (73) and 1.1 (14) percent of the data. Precisely 40 percent of the participants committed 74 percent of the errors, with 43 percent of the non-suppliance-in-obligatorycontexts errors occurring among clausal elements semantically indicating plurality. This implies that successful learning still eluded some learners despite the high level of exposure they got. Evidence of poor learning, ignorance of rules, over-generalisation, and inconsistency abound but only one incontestably L1-influenced error occurred.
\end{abstract}




\section{Keywords}

Morphology, Inflectional Morphology, L2 Learning, Acquisition of Morphology, ESL Acquisition

\section{Introduction}

The English -S plural morpheme is one of the most difficult grammatical morphemes to acquire and use by L2 learners (Behjat \& Sadighi, 2011), and there is a paucity of studies in its acquisition and use (Feng, 2012), compared to studies of verbal inflection (Haznedar, 2003) and grammatical morphemes in general (Akande, 2003). The few studies available utilise school pupils as subjects (Jia, 2003; Bliss, 2006; Jing et al., 2014; Ninpanit \& Pongpairoj, 2016) and, even where other inflections are studied, the focus has also been on incipient learners at the lower level of education, with little or no attention paid to the more advanced L2 learners (e.g. Amer, 2009). Where undergraduates are the participants, they tend to be students of remedial English or other similar programmes (e.g., Kato et al., 1999; Behjat \& Sadighi, 2011). So, the literature of L2 acquisition does not avail us of studies involving advanced learners studying for a degree in English who, most significantly, become English teachers at the lower level of education. It can rightly be argued that this category of university students no longer qualifies as learners in the true sense of the word learners. But they are learners still, though not at the basal level any more. Third-year students of English have acquired skills and knowledge that are technically unavailable to the average participant in previous morpheme studies: They have taken and passed courses in English Morphology, the English Nominal Group, and English Phonology (segments). After such diverse and extensive exposure to the grammar and phonology of the -S plural morpheme, it is assumed that errors associated with its use will not occur and that whatever errors still manifest must be fundamentally ontological and should be accounted for differently and in more radical ways.

The foregoing is the background against which this current study examines the acquisition and use of the -S plural morpheme by third-year undergraduate students of English in a Nigerian university. Its objectives are to: 1) identify all accurate and inaccurate instantiations of the $-S$ plural morpheme in a corpus of common nouns; 2) determine their frequency of occurrence and account for same; 3) specify the exact syntactic, lexical or semantic context of occurrence of each -S plural morpheme bearing or non-bearing common noun; 4) explain the continued occurrence of -S plural morpheme errors among this category of advanced L2 learners; and 5) suggest ways of improving L2 learners' acquisition and use of the English -S plural morpheme.

While it is expected that errors will occur, it is difficult to predict what pattern they will take in terms of variety and frequency. It is however envisaged that the outcome of this research will lead to revision of existing practices in English 
language teaching even at the university level. Of greater significance is the possibility of a study of this nature leading to the identification of what the real problems are with the acquisition and use of the -S plural morpheme by L2 subjects and how best to deal with them.

\section{Review of Literature}

This review of literature covers descriptive facts about the English -S plural morpheme and theoretical approaches to L2 acquisition studies.

\subsection{Descriptive Facts about the -S Plural Morpheme}

Some descriptive facts about the -S plural morpheme and their implications for the Nigerian L2 learner of English are hereby highlighted. As an exponent of the minimum grammatically meaningful unit of language (morpheme), the $-S$ plural morpheme is one of the chief inflectional affixes of English. It has as its locus number, one of the three systems that distinguish the word class noun from other word classes (The others are case and gender). Number denotes whether "one" or "more than one" is spoken of. There are thus two terms in the English number system, namely the unmarked singular (e.g., boy) and the plural marked by the addition of the morpheme -S to the base-form noun (e.g., boys). The distinction between singular and plural is primarily morphological; and, from the semantic point of view, its functions are, primarily referential (They refer not to the object or concept but to the referent of the given noun). While the regular plurals are almost always predictable in their spelling and pronunciation, the irregular plurals are not: The -S plural morpheme is represented orthographically as $-\boldsymbol{s}$ and $-\boldsymbol{e s}$ for the regular plurals. However, irregular plurals may require the voicing of a final consonant, for example, before the addition of $-s$ or -es (e.g., knife/knives). Phonologically, the $-\mathrm{S}$ plural morpheme is realised as $/ \mathrm{s} / \mathrm{,} / \mathrm{z} /$ or /iz/ depending on whether the base-form noun ends with a voiceless non-sibilant, voiced non-sibilant or vowel, or sibilant respectively (Adams, 1973; Christophersen \& Sandved, 1969; Strang, 1969; Quirk et al., 1985).

Nigerian languages are not marked for number in ways similar to English (There is a general absence of plural inflection). For example, Yoruba marks plural contextually, semantically, and morphologically using the 3rd person plural pronoun awon and the low toned won (Ajiboye, 2010). Igbo employs reduplication of nouns and syntactically determined plural markers, including the 3rd person singular pronoun ha, quantifiers, numerals, and special inherent plural words such as $n d i$ (Nweya, 2016). Andrew-Ogidi (2006) notes that Igala language uses derivational processes instead. These differences are veritable problem areas for L2 learners of English plurals.

\subsection{Theoretical Approaches to L2 Acquisition Studies}

Morpheme studies have been approached from a number of theoretical viewpoints in recent years, the most prominent of which are the Failed Functional 
Features Hypothesis (FFFH) and the Missing Surface Inflection Hypothesis (MSIH).

\subsubsection{The Failed Functional Features Hypothesis}

The Failed Functional Features Hypothesis fundamentally lies on the premise that the inventory of morphosyntactic features in any given language is not universal but subject to parametric variation and that learners' failure to supply an inflectional morpheme in their L2 is a morphosyntactic constraint rather than a phonological one. It stipulates that L2 learners do not acquire features that are not present in their L1 and that learners whose L1 grammars do not activate a given feature will not be able to acquire it in their L2. Furthermore, FFFH posits that features not acquired during the Critical Period are inaccessible to the L2 learner (Hawkins \& Chan, 1997; Bliss, 2006). It therefore follows that, since the feature [plural] is not activated in Nigerian languages, their speakers cannot learn plurals successfully. What then happens in cases of successful learning, which abound? FFFH seems to want to predict L2 learners' morphological problem in the manner of Contrastive Analysis (CA) without fully embracing its principles and techniques and without acknowledging the limitations of its predictive powers.

\subsubsection{Missing Surface Inflection Hypothesis}

The Missing Surface Inflection Hypothesis states that the absence of a morphological form or its variable use in L2 interlanguage grammar indicates a problem associated with the realisation of the surface morphology and does not result from an impairment in the representation of the associated functional projections of functional features. It posits that L2 learners' variable production of functional categories stems from a mapping problem from abstract syntactic representation to morphological instantiations. Variability concerning L2 production of functional morphemes is thus attributed to the processing problem that occurs only at the surface level. MSIH assumes that Universal Grammar (UG) is fully available for the L2 learner to make full use of and so are not restricted to only those features that are instantiated in their L2 (Hazendar \& Schwartz, 1997; Lardiere, 1998a, 1998b; Prévost \& White, 2000; Haznedar, 2003). In essence, MSIH would claim that Nigerian L2 learners have problems with English inflections because their L1 lacks them and that they can overcome those problems by appealing to UG. This is evidence of theoretical links to both CA and Interlanguage (IL). Oshodi (2014) has however demonstrated that missing overt inflection as a marked feature of L2 interlanguage grammars is not peculiar to Nigerian English.

Their relative recency and prominence notwithstanding, FFFH and MSIH evidently lack the power to satisfactorily explain successful and unsuccessful learning of English inflectional morphemes by the category of advanced L2 learners of English focused on in this study. Explanations for success in the acquisition of the -S plural morpheme, or, lack of it, require a more powerful the- 
ory of ESL acquisition. This may be found in the Combined CA-EA-IL theory.

\subsubsection{The Combined CA-EA-IL Theory}

The Combined CA-EA-IL theory is predicated on the premise that neither Contrastive Analysis nor Error Analysis (EA) nor Interlanguage is sufficiently powerful on its own to adequately account for how the L2 learner acquires their language. Credit for an ESL acquisition theory that combines all the positive features of CA (Lado, 1957), EA (Richards, 1974), and IL (Selinker, 1974) in order to make it more powerful and more efficient goes to Afolayan (1985). He formulated three propositions as follows.

Proposition I states that a theory of ESL is a theory of "errors" and it rests on three theoretical arguments. First, the ESL learner's total linguistic repertoire can only be a part and not the totality of the EMT/EL1, but will include all of the language elements of his MT/L1, which must be theoretically able to exert some influence on the language elements of EMT/EFL (TL) assumed as ESL elements. Second, an adequate theory of ESL must be a theory of EMT/EL1 minus the difference between EMT/EL1 (TL) and ESL, and must relate ESL to EMT /EL1 (TL) in order to show that they are variants of the same English language. Lastly, the difference between ESL and EMT/EL1 represents those language elements that are normally called errors and that differentiate SL learning and teaching from L1 learning and teaching.

Proposition II is a living tribute to Robert Lado and requires no elaboration since it merely acknowledges Lado as the father of CA and highlights his contributions in five major areas including teaching.

Proposition III argues that EA and IL are rather refinements of, and complements to, CA and that it is only a combination of CA and EA that can claim to be the powerful successor to CA alone, since CA is the more fundamental and older entity. While it admits that some CA-predicted errors may fail to actualise, it faults the claim that errors predicted by $\mathrm{CA}$ are not as significant as EA errors on the grounds that EA can only operate in "cultivated field" whereas CA can operate in both "green field" and "cultivated field". Moreover, since the target SL environment usually takes the form of the "green" rather than the "cultivated" field, the predicted errors are more significant because they function in both fields whereas actual errors do not function in the "green field" learning environment. Thus "an adequate theory of SL must be able to explain not only all the predicted and 'actual' errors but any discrepancy between the two". Furthermore, the various alternative terms for IL are descriptively significant because they point to the different stages of the TL achieved by the SL learner on the bilingual continuum. So, it becomes theoretically possible to see several interlanguages on the continuum as various stages in the realisation of "predicted errors". This therefore makes it more academically productive to tie IL to CA than to EA from the practical point of view. EA and IL are thus established as refinements and complements of CA.

The Combined CA-EA-IL theory of ESL acquisition is adopted for this work 
because it is comprehensive and can more efficiently handle the data at its various stages.

\section{Methodology}

\subsection{The Participants}

Third-year students of English Education at the Lagos State University make up the study population. Unlike their counterparts in the Faculty of Arts, they were exposed to English pedagogy through the compulsory English Methods course and the mandatory Teaching Practice exercise, which provided them with a different experience of the $-S$ plural morpheme. To obtain the sample, the researcher addressed the students after a class test, explained the purpose of the study and the nature of their involvement, requested and obtained fifteen volunteers. The sample size is approximately 10 percent of the study population and it is considered representative enough. Voluntary participation was opted for because of the demand that involvement in studies such as this makes on students' time. The volunteers comprise Yoruba and Igbo L1 speakers, IgboYoruba bilinguals, Ogu-Yoruba bilinguals, and an Ukwuani-Igala bilingual.

\subsection{The Instrument}

The research instrument was an essay test administered under strict examination conditions on 7 March 2019. The fifteen participants were instructed to write between 250 - 300 words on one of the following mutually agreed topics: "Our University Library", "INEC's Postponement of the Presidential Election", "Students and the IT World", and "My First Teaching Practice Experience". The scripts were retrieved immediately.

\subsection{The Data}

A manual word count of the fifteen essays was undertaken to determine the size of the corpus. There were 6103 words. Each script was thereafter carefully examined to identify and mark all the common nouns therein. These were subsequently copied out and counted. There were 1219 common nouns and this constitutes the data for this study.

\subsection{The Analysis}

Both quantitative and qualitative methods were employed for objectivity and comprehensiveness. The quantitative analysis which involves descriptive statistics and frequency counts proceeded in this order. Each of the 1219 identified and listed common nouns was critically examined in its context of occurrence to find out the presence or absence of number marking. Like Kato et al. (1999), irregular plural forms such as man/men were ignored since they are morphologically unrelated to the $-S$ plural morpheme. Four classificatory criteria were adopted for the common nouns in accordance with the defined objectives as follows: 1) suppliance of the $-S$ plural morpheme in obligatory contexts, 2) 
non-suppliance of the -S plural morpheme in obligatory contexts, 3) suppliance of the -s plural morpheme in non-obligatory contexts, and 4) non-suppliance of the $-\mathrm{S}$ of plural morpheme in non-obligatory contexts. Instances of each feature were identified and marked $o s$, on, $n s$, and $n n$ respectively. Their frequency was determined and the percentage relative to the data and the corpus was calculated. Error occurrence was determined by summing up on and ns cases, and its percentage relative to the data and the corpus was worked out. Correct usage was similarly determined by adding up instances of os and $n n$. The mean for the corpus, common nouns, and other parameters was separately calculated.

All the identified errors (that is, on and $n s$ occurrences) were further isolated in the larger context of the sentence in which the common nouns bearing each one occurred. This was aimed at ascertaining the exact type of nouns they are, the variant of the nominal group (NMG) structure they head, the type of modifiers preceding them (since this has a bearing on whether the count noun that follows is singular or plural), and the form of the verb in predicator position as this relates to grammatical concord. A similar analysis was undertaken for the $o s$ and $n n$ categories which, though pose no serious challenges because they are indicative of mastery of the form, are significant in the sense that this study is not a study of errors per se. Rather, it is a study of acquisition and use, and this necessarily entails accounting for both correct and defective usage. This was the qualitative dimension. It explored non-morphological parameters by combining both syntactic and textual analyses in order to find explanations for the different aspects of the data and enrich the study.

\section{Results}

What is presented in this section are the results of the data analysed. Tables and actual examples from participants' essays complement the presentation.

\subsection{Frequency Distribution of Common Nouns and the -S Plural Morpheme}

Table 1 displays statistical facts about how the -S plural morpheme fared in relation to the data and the corpus. The average number of words produced was 406, which means every participant theoretically exceeded the maximum 300 words prescribed. The 1219 common nouns that constitute the data represent 20 percent of the corpus size and gives an average of 81.3 per participant. Of this number, 905 representing 74.2 percent were not inflected for number because number marking for them is not obligatory $(\mathrm{nn})$. This was by far the largest subset and it gives an indication of the relative frequency of this category of nouns in English. Common nouns in contexts where plural marking is obligatory and was rightly marked followed distantly with 227 occurrences representing 18.6 percent of the data. These show that majority of the students recognised contexts in which suppliance of the -S plural morpheme was not required ( $n n)$ and respected the rule and contexts in which it was obligatory (os) and correctly supplied the form. 
Table 1. Suppliance and non-suppliance of the -S plural morpheme.

\begin{tabular}{|c|c|c|c|c|c|c|c|c|c|c|c|}
\hline $\mathrm{S} / \mathrm{N}$ & Participants & Corpus Size & Com.Nouns (Data) & $\%$ of Corpus & os & on & ns & $\mathrm{nn}$ & Errors & \%of Data & $\%$ of Corpus \\
\hline 1 & P1 & 409 & 75 & 18.3 & 14 & 2 & 3 & 56 & 5 & 6.7 & 1.22 \\
\hline 2 & P2 & 255 & 60 & 23.5 & 9 & 12 & 0 & 39 & 12 & 20 & 4.7 \\
\hline 3 & P3 & 315 & 79 & 25.1 & 16 & 1 & 1 & 61 & 2 & 2.53 & 0.63 \\
\hline 4 & P4 & 362 & 51 & 14.1 & 13 & 1 & 1 & 36 & 2 & 3.92 & 0.6 \\
\hline 5 & P5 & 408 & 98 & 24 & 25 & 0 & 1 & 72 & 1 & 1.02 & 0.25 \\
\hline 6 & P6 & 468 & 78 & 16.1 & 8 & 9 & 0 & 61 & 9 & 4.54 & 1.92 \\
\hline 7 & P7 & 598 & 93 & 15.6 & 3 & 16 & 0 & 74 & 16 & 17.2 & 2.7 \\
\hline 8 & P8 & 449 & 93 & 20.7 & 17 & 7 & 2 & 67 & 9 & 9.7 & 2 \\
\hline 9 & P9 & 244 & 74 & 30.3 & 14 & 5 & 3 & 52 & 8 & 10.81 & 3.3 \\
\hline 10 & P10 & 466 & 98 & 21.03 & 17 & 0 & 0 & 81 & 0 & 0 & 0 \\
\hline 11 & P11 & 303 & 68 & 22.4 & 20 & 4 & 0 & 44 & 4 & 6 & 1.32 \\
\hline 12 & P12 & 427 & 78 & 18.3 & 30 & 1 & 1 & 46 & 2 & 2.6 & 0.47 \\
\hline 13 & P13 & 493 & 97 & 19.7 & 9 & 10 & 0 & 78 & 10 & 0.82 & 1.82 \\
\hline 14 & P14 & 420 & 92 & 22 & 19 & 3 & 0 & 70 & 3 & 3.3 & 0.71 \\
\hline \multirow[t]{5}{*}{15} & P15 & 426 & 85 & 20 & 13 & 2 & 2 & 68 & 4 & 4.71 & 0.94 \\
\hline & Total & 6103 & 1219 & 20 & 227 & 73 & 14 & 905 & 87 & 7.14 & 1.43 \\
\hline & $\%$ of Corpus. & & 20 & 0.33 & 3.72 & 1.21 & 0.21 & 14.8 & 1.43 & & \\
\hline & $\%$ of Data & & & 1.64 & 18.6 & 6.1 & 1.1 & 74.2 & 7.14 & & \\
\hline & Mean & 406 & 81.3 & 1.33 & 15.1 & 4.93 & 0.9 & 60.3 & 5.8 & & \\
\hline
\end{tabular}

With the other two criteria the -S plural morpheme was either omitted in contexts where its suppliance was obligatory (on), and this was by far higher with 73 instances representing 6.1 percent of the data, or, was supplied in non-obligatory contexts $(n s)$, which represents 1.1 percent with 14 occurrences. In essence, 87 forms representing 7.14 percent of instances of common noun usage and 1.4 percent of the 6103-word corpus were erroneous because users either failed to supply the $-S$ plural morpheme where they ought to or did so where they ought not to.

Error mean was 5.8 but the rate varied considerably according to participants. While the highest was 20 percent of data, the lowest was 1.03 percent, with one student posting 0 percent. These variations are indications of individual participant's level of mastery of the -S plural form. For example, P7, P2 and P13 recorded the highest of 16, 12 and 10 errors respectively and all involved nonsuppliance of the $-\mathrm{S}$ plural morpheme in obligatory contexts. There were also variations in the number of suppliance in obligatory contexts. Take P7, who 
supplied rightly only in 3 instances, recorded 0 suppliance in obligatory contexts and had 76 cases of non-sppliance in non-obligatory contexts, as a case in point. The -S plural form does not seem to exist in the list of morphemes acquired by them, and the question of correct usage does not seem to arise either. They simply failed to acquire the form as form. Indeed, just 40 percent (6) of the participants accounted for 81 percent (59) of the 73 on-type errors, with P7 alone contributing 22 percent (16). It does appear that some individuals will most certainly fail to learn a given subject matter irrespective of the length and depth of exposure they get.

To appreciate the uniqueness of each of the $n s$-type and on-type errors, all the 87 common nouns implicated in the incorrect use or non-use of the -S plural morpheme were further subjected to close scrutiny in the context of their clauses. This helped to determine their subclasses and identify the structural variants of the nominal groups they head. The number manifesting each feature was ascertained (See Table 2 below).

Whereas Table 1 above shows that omission of the $-S$ plural morpheme where it is obligatory was dominant over its use where it is not obligatory, Table 2 displays the exact context of omission or insertion and each one's frequency of occurrence. It shows that whereas four were associated with failure to supply the plural marker where it is obligatory, three were in respect of its use in nonobligatory contexts. Significantly, the contexts of occurrence of the ns-type and on-type errors were syntactically and lexically different. The on-type errors were associated with plural invariant nouns and all the structural variants of the nominal group, while the $n s$-type errors featured among count nouns, mass nouns and nominalisations, with the first manifesting more as structurally MH-Type and the others H-Type only. Indeed, approximately 43 percent (31) of the 73 on-type errors occurred in other obligatory contexts with clausal elements semantically indicating plurality. It is instructive that by far the most recurring is the incidence of not inserting the marker of plurality where the context of occurrence of the noun clearly indicates "two or more" entities. Could the absence of plural inflection in the participants' L1 be responsible for the omission? It is difficult to answer in the affirmative because the set of participants that committed these errors share similar linguistic backgrounds with the rest.

Table 2. Typological and structural classification of -S plural morpheme errors.

\begin{tabular}{|c|c|c|c|c|c|c|c|c|}
\hline $\begin{array}{l}\text { Error } \\
\text { Type }\end{array}$ & $\begin{array}{l}\text { Count } \\
\text { Nouns }\end{array}$ & $\begin{array}{c}\text { Mass } \\
\text { Nouns } \\
\text { (H-Type) }\end{array}$ & $\begin{array}{c}\text { Nomi } \\
\text { nalisa } \\
\text { Ions } \\
\text { (MH-Type) }\end{array}$ & $\begin{array}{c}\text { MH/ } \\
\text { MHQ-Type } \\
\text { NMG }\end{array}$ & $\begin{array}{c}\text { H/HQ-Type } \\
\text { NMG }\end{array}$ & $\begin{array}{c}\text { Plural } \\
\text { Invariant } \\
\text { Nouns }\end{array}$ & $\begin{array}{c}\text { Semantically } \\
\text { Obligatory } \\
\text { Contexts }\end{array}$ & Total \\
\hline on & - & - & - & 18 & 16 & 8 & 31 & 73 \\
\hline ns & 10 & 3 & 1 & - & - & - & - & 14 \\
\hline Total & 10 & 3 & 1 & 18 & 16 & 8 & 1 & 87 \\
\hline
\end{tabular}


A peep into what to expect next and the activities leading to it is necessary at this juncture. Since the modifier and the subtype of the noun lexeme it precedes influence number marking in different ways, special attention was paid to both. Each common noun's context of occurrence was carefully studied using known syntactic and lexical parameters, such as whether or not the modifier is an article or an adjective. This task was aided by the DOEN (Determiner, Ordinal, Epithet, Nominal) structure of the modifier system. The status of the noun lexeme itself was also ascertained in terms of the binary oppositions of count $\mathrm{v}$ mass, singular $\mathrm{v}$ plural, and singular invariable $\mathrm{v}$ plural invariable as well as nominalisation. These are overt features in the immediate vicinity of the -S plural morpheme bearing or non-bearing common noun in headword function. But there remains textual considerations. So, it became necessary to also examine the larger context of the sentence and beyond for evidence of semantically obligatory contexts for plural marking. This was done for all the four criteria. However, because of the amount of data involved and because of its little analytical value, determining the exact number of times each identified form preceded a common noun was not pursued further for the os and $n n$ subsets.

In the presentation that follows, samples of each syntactic or lexical parameter are first listed before sentential examples are provided where necessary.

\subsection{Suppliance of the -S Plural Morpheme in Obligatory Contexts (os-Type)}

It emerged from the analysis that 227 common nouns representing 18.6 percent of the data were instances where the -S plural morpheme was obligatory and was duly supplied. This is evidence that the participants recognised obligatory contexts for $-S$ plural morpheme usage and inserted the form accordingly. The various contexts are as detailed below.

\subsubsection{Determiners}

\section{(a) The Definite Article}

One syntactic attribute of the definite article the is its capacity to precede both singular and plural count nouns, unlike its indefinite counterpart that is restricted to co-occurrence with singular count nouns only. The list and excerpt below show that the participants recognised this grammatical fact and inflected the count nouns appropriately.

(1a) the exams the citizen $s$ the action $s$ the student $s$ the reason $s$ the merit $s$ the shift $s$ the demerit $s$ the teacher $s$ the mosquitoes the abilities the youth $s$ the trader $s$ the danger $s$ the mind $s$ the learner $s$

(1b) Finally, I went inside my school of practice and I was welcomed by the principal

... She introduced me to the teachers and the students.

\section{(b) Pronouns}

Personal pronouns, demonstrative pronouns, and invariable determiner pronouns served as determiners. Personal pronouns semantically indicating plural, 
together with some singular ones, were correctly used before plural count nouns as (2a) shows.

(2a) their polling units/classmates/friends/challenges/achievements/classes/duties our supervisors/leader $s /$ dear teachers/classmates/classes

my course mates/questions/peers/most admired teachers/students/

his or her learners her manners other members

Plural demonstrative pronouns that obligatorily allow plural nouns to follow them served as determiners too:

(2b) these acts/bad habits those persons

Invariable determiner pronouns preceding plural count nouns are quantifiers and are indicators of plurality themselves. Some of them are listed here with their co-occurring nouns.

(2c) some year $s /$ Nigerian $s /$ thing $s /$ minute $s$

many sphere $s$ and phase $s /$ factor $s /$ ways/serious student $s$

most classe $s /$ student $s /$ case $s /$ times

such pupils all kind $s$ all necessary item $s$ a few bad habits

Below are excerpts showing plural count noun headwords with different pronouns as modifiers.

(2d) In addition, the lives of people who had travelled down to their polling units were left in jeopardy.

... If those persons had some sort of accidents on the way, on whose account would that be?

(2e) ... the process of the election was almost hijacked by some political thugs and hoodlums.

(2f) Many serious students compile books as a result while others can easily learn one skill or the other through video technology.

\subsubsection{Ordinators}

Count nouns occurring after cardinal numerals other than "one" are obligatorily inflected for number, and the participants seemed to have learnt this rule well and applied it correctly as (3a) and (3b) show.

(3a) four years the four walls eight years more than two parties 40 minutes the three classe $s 107$ students 10 state 23 state $s$

(3b) The total number of 23 states was prepared for the election while 10 states were unprepared.

\subsubsection{Epithets}

Adjectives realise epithets (E) which function as an element of the modifier structure. No colour adjectives preceded plural nouns, but there were several of those denoting inherent attribute and one of provenance as (4a) shows.

(4a) meaningful thing $s$ logistical challenges economic activities petty trader $s$ brilliant students

electoral officers domestic issues pessimistic thoughts additive behaviours lazy ones 
negative aspects virtual games time-consuming activities foreign countries new friend $s$

useful materials bad teachers good grades different discipline $s$ mathematical problems

senior friend $s$ senior colleagues major reasons private $\operatorname{school} s$ electoral logistics

Excerpts (4b)-(4c) illustrate epithets with plural nouns.

(4b) It is bad news for those who do not see the harm in quitting additive behaviours that are associated with the IT world. I will mention but a few bad habits that people do and do not take cognisance of.

(4c) At the news of the TP registration ... myriads of pessimistic thoughts seared my heart.

One epithet realised by an adjective semantically indicating more than one is in:

(4d) Nigeria is a multi-ethnic country with diverse cultures.

\subsubsection{Nominals}

Nominals occupy the last sloth $(\mathrm{N})$ in the DOEN structural formula for the modifier and they preceded plural count nouns. Notice that coordination makes the $-S$ plural morpheme even more compelling in (5a).

(5a) computer games English teacher $s$ English students curse words burial and marriage ceremonies

(5b) In most cases English teachers were not sent.

\subsubsection{Plural Invariable Nouns and Nominalisations}

The headwords in (6a) are plural invariable nouns that occur as plural only, nouns that usually occur as plural (tears), and nominalisations (happenings only). All were inflected accordingly as (6b) further illustrates.

(6a) a valid mean $s$ volunteer corp $s$ goose-bumps (about) happening $s$ their good $s$ her manner $s$ (on) logistics electoral logistic $s$ (moved to) tear $s$

(6b) It was not like I had not had a teaching experience before. I once had and that was in a volunteer corps, which was like an extra lesson.

\subsubsection{The H-Type/HQ-Type Nominal Groups}

Only plural nouns function as headwords in H-Type and HQ-Type nominal groups, which makes it obligatory to inflect any count noun in such contexts. Again, the participants seemed to have learnt this well enough to achieve correct plural marking as (7a) suggests. Notice the observance of number concord with existential there as subject in (7b) and its non-observance in (7d).

(7a) question $s$ student $s$ non-student $s$ live $s$ dutie $s$ thing $s$ gift $s$ generation $s$ drink $s$ speaker $s$ myriad $s$ lecture $s$ test $s$ assignment $s$ pupil $s$ mark $s$ goodies movie $s$ game $s$ prefect $s$ teacher $s$ volunteer $s$ friend $s$ lesson $s$ session $s$ sentence $s$ days month $s$ rumour $s$ particle $s$

(7b) There are students who seize the medium to achieve a lot of meaningful 
things for themselves.

(7c) A teacher loses nothing for teaching something wrong but a student loses marks for writing something wrong.

(7d) It was difficult to cope ... Questions was (sic) just running my mind (sic), such as, how will I face this supervisor, what will I say to him ...?

A phonologically-induced orthographical error occurred due to non-observance of the rule requiring voicing of the last fricative before adding the -S plural morpheme. Yoruba lacks the voiced labiodental fricative $/ \mathrm{v} /$ and so there is a strong L1 influence in the realisation of lives as lifes in (7e) below. However, poor learning cannot be ruled out since two participants produced the correct plural form (See (2d) and (7a) above)).

(7e) I savoured the thought of finally assuming the position of a teacher and, like my most admired teachers, impart (sic) lifes just as they did me.

\subsection{Non-Suppliance of the -S Plural Morpheme in Non-Obligatory Contexts (nn)}

The 905 instances of non-suppliance of the -S plural morpheme in contexts where it is not obligatory to do so are the focus of this subsection. Singular count nouns and mass nouns are unmarked for number and are generally selective of the type of syntactic company they keep with respect to modifiers. Given that the subset of the data we are dealing with here represents 14.8 percent and 74.2 percent of the corpus and data respectively, with the mean for the 15 participants put at 60.3 , it is not out of place to infer that the participants have mastered the rule for non-suppliance of the plural form and carefully refrained from violating it. Once again, the presentation begins with determiners.

\subsubsection{Determiners}

Because of the limited potential for co-occurrence with singular count nouns and mass nouns already noted, the type of determiners that can precede these subclasses of nouns are expectedly restricted. Except for determiner proper the which makes no semantic distinction with regards to number, the rest are invariably singular in semantic orientation. Consequently, only the indefinite article $a$ and pronouns semantically indicating "one" or "not more than one" can also precede singular count nouns.

\section{(a) The Definite Article}

Lists (8a) and (8b) respectively display samples of singular count nouns and mass nouns with the as modifier, but exclude mass nouns with dual class membership because it is the presence of modification that makes them countable as well (e.g., the interest).

(8a) the university the month the classroom the school the way the list the idea the end

the headmistress the thought the class the principal the district the name the colour

the uniform the process the phone the video the internet the rumour the IT 
world

the tertiary institution the same secondary school the set day the INEC boss

(8b) the glamour the goodness the commencement the credibility the postponement the unwillingness the invention the stress

Some more are illustrated in context as follows.

(8c) The world has become a global village due to the invention and popularity of information technology.

(8d) The speech was delivered with ( $\mathrm{sic}$ ) a sobriety mood, revealing the unwillingness of the INEC chair to postpone the election.

(8e) How will I cope since the TP programme will run simultaneously with lectures in school?

\section{(b) The Indefinite Article}

The lists and textual examples in (9a)-(9d) illustrate singular count nouns with the indefinite article $a$ and its phonologically determined variant an as determiners.

(9a) a youth a person a guide a teacher a learner a week a day a result a woman a teaching experience a primary school a nice person a medium a bona fide student a good relationship a multi-party system a shocking surprise a number of people a beautiful experience a very friendly way a soothing relief a loving heart

(9b) an experience an example an extra lesson an uneasy goat an eye opener an unforgettable experience an agent an end

(9c) $A$ wonderful comment was given by my supervisor; and this encourages (sic) me to have more interest in the teaching line.

(9d) The electoral exercise, if done on the initial date, would have left a number of people disenfranchised.

(9e) It was indeed an unforgettable experience, an experience that motivates and gives me new knowledge about how (sic) academic system is run in our dear country, Nigeria.

\section{(c) The Pronoun}

Two sets of determiner pronouns, demonstrative pronouns, and quantifier pronouns precede singular count nouns. They are those semantically indicating singular (e.g., $m y$ name) and those, despite being semantically plural, are regarded as one and the same entity with their referents(e.g., our nation). For mass nouns, the pronouns are either singular (e.g., his presence) or plural (e.g., their franchise). What follows sets out and illustrates the various pronoun types and their accompanying common nouns.

(i) Determiner Pronouns

Singular count nouns and mass nouns with determiner pronouns as modifiers 
are shown in (10a) and (10b) respectively. While (10c) shows their capacity for co-occurrence, (10d) is a case of apposition in which the presence of the 1st person singular pronoun me rules out a plural noun as its co-referent.

(10a) my choice my mind my way my name my final year my great country my cooperative teacher our nation our purpose our dear country their teacher his/ her student its chair other academic staff

(10b) myarrival my freedom my dress sense their previous knowledge their franchise our money his presence no doubt her love

(10c) The day my supervisor came, he commended my dress sense first, then asked me for my lesson note. I finally taught in his presence.

(10d) I was so afraid the students were going to bully me, their teacher.

\section{(ii) Demonstrative Pronouns}

Only singular demonstratives feature in contexts where the use of plural marker is not obligatory as (11a)-(11b) show.

(11a) this exercise this time this feeling this method this multitude this tiny voice this week this same school this way that minute that situation that day that election that morning

(11b) I started $\ldots$ by asking my students how they spent their Christmas holiday, where they went to and what they ate on that day. I started this way to create a comfortable environment for me and my students.

\section{(iii) Quantifiers}

Whereas quantifiers such as much and its derivatives obligatorily precede mass nouns, and every and each denoting "not more than one" come before singular count nouns, any occurs with both singular and plural count nouns (e.g., any question/questions?). The different quantifiers and the nouns that follow them are hereby listed and illustrated.

(12a) much information more interest more time more experience most people

any moment any college of education any institution anyletter every pre-service teacher every student each week all my life

(12b) The idea was that those who teach in government schools will have more experience than the others in private schools, which was a misconstrued idea.

(12c) Every pre-service teacher or teacher-in-training is expected to undergo the teaching practice programme. An announcement had been made summoning every student of education to register.

\subsubsection{Ordinators}

Only the cardinal numeral one can modify singular count nouns. However, there was the special use of one hundred and two hundred with the mass noun level (100 Level/200 Level) to denote the position of a group of students relative to the degree in view in, say, a four-year degree programme. In contrast, ordinal nu- 
merals in the data were more diversified. Cardinal and ordinal numerals modifying singular count nouns are listed in (13a) and (13b) respectively and shown in sentence context in (13c)-(13f).

(13a) one year one great fear one skill one state

(13b) my first day my first class my first valentine my first threat my first lesson

my first encounter my first teaching practice my second class

the second week

the second period the next day the next one the next morning

my last day the last year the twenty-first century

(13c) My students still call me even after one year of teaching and being away from them.

(13d) Though it was an experience I anticipated since my 100 Level ... (Compare: My cooperative teacher took me to the $S S 2$ classes)

(13e) It is a pleasure talking about my first TP experience ... My last day in my teaching practice school makes me realise ...

(13f) It is no doubt that the twenty-first century is indeed a lucky age.

\subsubsection{Epithets}

Different subclasses of adjectives function as epithets in the modifier structure. Significantly, the headwords they precede are count nouns and mass nouns requiring no plural marking as (14a) and (14b) respectively show.

(14a) a very brave and commendable one a very good discovery long story the pasted list

a non-democratic one a free and fair election a great help/relief

a global village

singular action the best TP student unanticipated emergency

a wonderful experience

my greatest nightmare electoral post/exercise/committee a new thing a lingering fear

a developing democracy the brown envelope a blue shirt a black suit

(14b) overwhelming joy irredeemable time late arrival in great fear bad weather

my new look human life distant people new knowledge mass preparation

Extracts (14c)-(14d) and (14e)-(14f) respectively illustrate some more singular count nouns and mass nouns with epithets as modifiers. Notice contextual indicators of singularity (another, was) in (14c) and the occurrence of a derived adjective in (14f).

(14c) Another sweet experience I had was the teaching aspect.

(14d) My cooperative teacher was always happy with me.

(14e) The reason for writing this piece is to lampoon the barbaric nature of postponing the election. 
(14f) I resumed the first day with trepidation in my heart. There was a lingering fear in my heart.

\subsubsection{Nominals}

Nominals occupy the last slot in the DOEN structure as earlier stated. Like the nouns that immediately follow them as headwords, they can be realised by singular count nouns or mass nouns. List (15a) outlines the diverse combinatorial possibilities of nominals and their common noun headwords with regards to singular count nouns (S) and mass nouns (M) while (15b) illustrates one in context.

(Both S): sentence construction the government school student teacher lesson note school timetable

(Both M): morning assembly my dress pattern/sense/code security personnel information technology information reservoir

(M \& S): a blame game this education process teaching practice/profession/ experience

(S\&M): video technology

(15b) However, as important as information technology is to students, many of them misuse the window or system.

\subsubsection{Singular Invariable Nouns}

The only singular invariable noun in the data is news:

(16a) good news bad news the news

(16b) The bad news was failing the teaching practice as a course ...

\subsubsection{Mass Nouns}

To demonstrate that the mass nouns in (17a) are H-Type nominal groups, all relevant details before or after the node are excerpted and bracketed.

(17a) (gave me) joy (out of) luck (is) education (passing) knowledge (in) panic (of) fulfilment (of) truth (and) classwork (persuading) people (use) comic (took) courage (in) jeopardy (of) attestation information (transforms)

(of) belongingness people (do not) (by) air (have) interest (garnering) experience

A few more examples in their sentence context will suffice.

(17b) Our supervisors come for supervision unannounced.

(17c) ... but we need the spirit of unity and togetherness to fight corruption and eradicate embezzlement of fund (sic) totally from our nation.

\subsubsection{Nominalisations}

List (18a) contains virtually all the nominalised forms seen. It is clear that they require no plural form and are therefore unmarked for number, as unknown further confirms in (18b).

(18a) teaching learning (on-line) chatting streaming cleaning zero-rigging cyber-bullying (the) turn-out (for ) evil writing 
(18b) I arrived my place of duty everyday at $7.45 \mathrm{am} . .$. with the fear of the unknown (my supervisor).

\subsection{Suppliance of the -S Plural Morpheme in Non-Obligatory Contexts (ns-Type Errors)}

The 14 cases of -S plural morpheme suppliance in non-obligatory contexts involved 10 count nouns, 3 mass nouns, and 1 nominalisation. What their pluralisation represents is the erroneous extension of the rules of plural formation to contexts where they do not apply.

\subsubsection{Count Nouns}

It is useful to further classify the non-obligatory contexts where count nouns were inflected into two types. The first covers modifiers semantically indicating "one" or "not more than one" and the second can simply be referred to as "other non-plural contexts". Unlike what was seen in 4.3 .1 above, count nouns preceded by the indefinite article $a$ and quantifier pronouns such as every were wrongly marked for number, as the nominal group heads in (19a)-(19c) show.

(19a) a group charts every affairs of election every other parties to each centres

(19b) All the same, we started a group charts and decided to enjoy the evenings (sic).

(19c) Every other parties are not recognised, which is not meant to be.

The insertion of the -S plural morpheme in other non-plural contexts reveals an underlying problem that is best understood within the global context of use. So, with the probable exception of my names in (19e) below, it makes no sense to list them because they do not easily lend themselves as errors if de-contextualised. Consider the electoral bodies in (19d) below and the evenings in (19b) above, whose inflection is not matched by the context of use. Although there can be two or more electoral bodies and many evenings, there is only one electoral body in Nigeria known as the Independent National Election Commission (INEC), and there actually was only one evening referred to and that was the eve of the postponed election.

(19d) I appeal to the electoral bodies to take the election of 4 years very serious (sic), and make sure nothing like this never occur (sic) again.

Coming back to my names, it is tempting to attribute its inflection to the participant's Yoruba L1 background in which children are given multiple names at birth. But, the Yoruba do not normally introduce themselves using the plural pronoun marker for number thus: Awon oruko mi ni ... (My names are ...). Instead, they say: Oruko mi ni ... (My name is ...), which is what one participant rightly did in (10a) above. So, could this error have been caused by hyper-correction? Here is the context.

(19e) She introduced me to the class as a student teacher and I was asked to tell (sic) my names. 
The next set of items is different because its error source is both syntactic and semantic. The first, most, is both a plural quantifier pronoun (See (12a) above)) and a periphrastic comparison form used before certain disyllabic adjectives. As a superlative marker most makes no reference to number whatsoever but to "a higher degree". However, as (19f) reveals shortly, the participant might have reckoned that the same meaning applies for its pronoun and adjective classes and went ahead to inflect the noun headword. Notice the semantic incongruity between the 1st person singular pronoun as subject $(I)$ and the plural noun headword in complement position (students).

(19f) I may not be the most brilliant students amidst my peers but what gave me joy was the fact that my choice of course was given given to me.

The same participant produced the second item shown in (19g). Disregard the tense error and it is not difficult to identify an -S plural morpheme error or a potential number error with respect to lexical $\mathrm{BE}$, if it is acknowledged that a teacher can deploy one or more teaching aids in lesson delivery.

$(19 \mathrm{~g})$ It was that minute I remembered that my instructional materials isn't (sic) ready.

The last item relates to the noun lexeme claim, which occurs only as singular in the context of the $\mathrm{x}+\mathrm{g}$ non-finite verb laying to produce the idiomatic form laying claim. Its pluralisation could have been caused by ignorance about laying claim being a fixed collocation and its syntactic contiguity with students. The participant must have rationalised that since their "students" were many, "claim" should match the number morphologically. This is over-generalisation of rules as the context exposes further.

(19h) The teachers in the school were so happy for me. The students were laying claims that they pitied me.

\subsubsection{Mass Nouns}

The three wrongly inflected mass nouns are the H-Type nominal groups $h u$ mours, researches and personnels. Each noun's context of occurrence appears to offer some explanations for its pluralisation. For example, it is most probably the case that humour was not recognised as an uncountable noun despite its coordination with another mass noun comic, which was rightly not inflected. Its coordination with a count noun marked for number might have influenced the inflection of personnel, in apparent adherence to the rule requiring coordinated items to be of equal grammatical status. So, this too is a case of hyper-correction. Although there is an increasing use of research as a countable noun against all known grammatical rules (Careful writers never do), its co-occurrence with happenings in parallel clauses may have caused it to be marked for plural. Here are the excerpts.

(20a) I had to use comic and humours on them to forget about the supervision.

(20b) One of the major reasons for the postponement of the election was that of logistics issues which varied from inadequate electoral materials to personnels. 
(20c) They need information to do researches, they need information to find out more about happenings around the world, which will keep them updated.

\subsubsection{Nominalisations}

As a deverbal noun teaching is inherently a mass noun. But, it also occurs as teachings meaning a doctrine. Two factors explain its pluralisation in the classroom context. The first is ignorance about its meanings and the contexts in which they apply. The second appears to me to be a desire on the participant's part to aggregate their efforts. Having taught several topics to several pupils in several lessons for several weeks, they must have reckoned that these activities could not be adequately captured using a singular noun. This is a case of overgeneralisation and extension of rules to contexts where they do not apply. As (21) shows, the classroom is quite remote from religious contexts where teachings is more suitably used.

(21) I was handling not less than 107 students during my teachings.

\subsection{Non-Suppliance of the -S of Plural Morpheme in Obligatory Contexts (on-Type Errors)}

The data records failure to supply the $-S$ plural morpheme in 73 contexts in which its suppliance is obligatory, which constitutes errors. Table 2 classifies them into four subtypes according to whether they relate to plural invariable nouns, MH-Type/MHQ-Type nominal groups, H-Type/HQ-Type, or other obligatory plural contexts. Each category is critically examined as follows.

\subsubsection{Plural Invariable Nouns}

Plural invariable nouns occur as plurals only. They are so named because they do not result from the pluralisation of singular nouns and must therefore be learned and stored in the memory as a whole. The data contains 8 such nouns that were left bare without the obligatory -S plural form probably due to inappropriate learning strategy and ignorance of their morphological status with respect to number. All are listed as (22a).

(22a) the surrounding (2ce) bad weather condition the shortcoming embezzlement of fund (See (17c) above)) early hour no limit or bound

As (22b)-(22d) further prove, the -S plural morpheme is obligatory in the context in which they were omitted.

(22b) The postponement of the National Election which was scheduled to hold for (sic) February 16 was announced ... at the early hour of the day by 3.00 am.

(22c) I was also given a post to take care of the surrounding by appointing students to handle the cleaning.

(22d) I believe Nigeria is a great country where my freedom has no limit or bound, but we need ...

\subsubsection{MH-Type and MHQ-Type Nominal Groups}

In 4.2.1(b) above, it was shown that the -S plural morpheme was correctly sup- 
plied in obligatory contexts after determiner pronouns and cardinal numerals semantically indicating "more than one". It was similarly acknowledged that the plural morpheme was rightly not supplied in non-obligatory contexts such as after the definite article and quantifiers signifying "one" or "not more than one". These were indications that rules for plural formation and usage were properly learned and correctly applied. What this sub-section presents however tends to question the inferences earlier drawn because the same rules that had been obeyed now seem to have been flagrantly flouted. The relatively small number of common nouns affected notwithstanding, this is a manifestation of inadequate learning since the same set of learners appear to have been unable to apply the rules consistently.

For a clearer picture of the syntactic contexts to emerge, all the 18 nominal groups were analysed into their elements of group structure (See Table 3 below), with the exact modifiers and headwords italicised. Notice how the conjoined nouns in No. 5 provide further evidence of inconsistency: The one has the plural marker and the other does not. Notice also that although the in No. 17 does not

Table 3. Structural analysis of non-suppliance in obligatory contexts.

\begin{tabular}{|c|c|c|c|c|c|c|}
\hline $\mathrm{S} / \mathrm{N}$ & & & M & & $\mathrm{H}$ & Q \\
\hline & $\mathrm{D}$ & $\mathrm{O}$ & $\mathrm{E}$ & $\mathrm{N}$ & & \\
\hline 1. & many & & & & part & \\
\hline 2. & & five & zonal & & airport & \\
\hline 3. & their & & & & vote & \\
\hline 4. & some & & & & conversation & \\
\hline 5. & some & & & & shirt and skirts & \\
\hline 6. & & & different & & experience & \\
\hline 7. & all & & educational & & school & \\
\hline 8. & all & & & university & faculty & of education \\
\hline 9. & our & & & & letter & \\
\hline 10. & all & & & & school & \\
\hline 11. & their & & own & & letter & \\
\hline 12. & our & & cooperative & & teacher & \\
\hline 13. & all the & & & & teacher & \\
\hline 14. & their & & own & & town & \\
\hline 15. & our & & national & & issue & \\
\hline 16. & all & & born & & teacher & \\
\hline 17. & the & & & & politician & \\
\hline 18. & & & great & & expectation & \\
\hline
\end{tabular}


inherently select number, whether morphologically or semantically, only a plural count noun is possible when viewed against the global context of its use (See (23g) below)). The noun expectation has dual class membership with respect to number. It is always plural when count, which makes its non-inflection an error (See (23f) below)).

The following excerpts illustrate some of the items in their different contexts.

(23a) In spite of the fact that INEC created five zonal airport to facilitate the delivery of electoral logistics ...

(23b) Although the nation experience (sic) mass preparation for the election and people travelling (sic) from one place to another a day to the election in order to cast their vote...

(23c) I had to borrow some shirt and skirts because I hardly wear them ...

(23d) Teaching Practice ... happens to be a course in all university faculty of education.

(23e) ... the traders that travelled to their home town

(23f) I arrived my place of duty everyday at $7.45 \mathrm{am}$ with great expectation from my students ...

(23g) In conclusion, this postponement has led to lost (sic) of interest by the citizens. This interest can only build (sic) again by the politician which makes the INEC to give room for campaign ...

\subsubsection{H-Type and HQ-Type Nominal Groups}

Only plural count nouns function as headwords in H-Type and HQ-Type nominal groups, and 300-Level English students ought to be aware of this fact. Yet some went ahead to make singular count nouns heads of these structural variants, committing errors in the process. The following are the 16 singular count nouns in wrong headword function.

(24a) H-Type: result shirt student student gift prayer mat bucket semester location attempt election

(24b) HQ-Type: faculty of education source of information method of teaching

thousand of students

Their contexts of occurrence clearly reveal evidence of poor knowledge and inconsistency in application of rules. Take (24c)-(24e), for example, where, in the same sentence, plural is rightly marked in some nouns (bold) but unmarked in others (italics) requiring it.

(24c) After the exams, we were expecting result and expecting the pasted list. Thousand of students in the College had sleep (sic) night on that very day of the list.

(24d) The Independent National Electoral Commission (INEC) is the body that conducts election in my country, Nigeria ... There were supposed to be provision of things like mat, bucket, speakers for entertainment and even drinks. 
(24e) Days, months, semester and sessions came by; I maintained good grades.

The failure to mark plural in the two occurrences of student in (24f) demonstrates how difficult learning and using the -S plural morpheme can be for some persons whose L1 lacks morphological marking for number. This is in spite of the participant's apparent self-consciousness about the referent of Student 1 being more than one, which is evident in the 3rd person plural pronoun them, and despite Student 2 being co-referential to them.

(24f) But there wasn't interest in learning in my student. I said to myself ... you need reinforcement to make them (student) have interest in your teaching.

Consequently, once the -S plural morpheme was omitted where it ought to have been added in a case of coordinated count nouns, concern for number concord was relegated.

(24g) A small get together was thrown on our behalf and gift and prayer was (sic) showered on us.

\subsubsection{Other Obligatory Plural Contexts}

There were 31 unmarked plurals in obligatory plural contexts (See Table 2). What sets this group apart from those already examined are the presence of semantically plural items in the larger context of the clause in which they occur and the corresponding absence of modifiers signifying two or more entities. The items make pluralisation obligatory for the count noun in headword function as subject or complement or both. The uniqueness of this aspect of the data demands that as much of the context of occurrence of each noun in question as relevant for meaningful interpretation be excerpted. This makes further contextual illustration unnecessary. The list is as follows.

1) ... the late arrival of result sheet in many part (sic) of the country

2) Furthermore, transportation of materials relied on slow moving, long vehicle...

3) ... INEC also faced what may well be attempt(sic) to sabotage its preparation,

4) which includes serious fire incident in three of its offices.

5) I was scared of the students, the teachers and my co-teaching practice student.

6) My greatest nightmare ... was wearing of corporate suit.

7) I started buying new suit each week.

8) It made me to have different experience(sic) in life, especially the experience of ... writing lesson note.

9) My cooperative teacher assisted me a lot because she helped me to construct my teaching aid

10) My first day ... was a beautiful experience which I had with my fellow colleague from the same institution.

11) She told us she won't be able to accept the letter except ...

12) ... which me and my colleague did. 
13) Finally we got the letter and immediately headed back to the school.

14) My TP experience happen (sic) to be one of the memorable day...

15) ... since I was supposed to be among the INEC official.

16) From my discussion with other members ...

17) These acts have destructive effect on students and

18) it (sic) causes serious setback

19) to the student and

20) kills more time the student actually might use to read ...

21) My first teaching practice experience was one of the best experience of my life.

22) A teacher that is not ready to accept the idea

23) of his/her student ...

24) "We are all born teacher" (sic), she said to my student

25) ... but there wasn't interest in learning in my student

26) ... giving out things to my student whenever they attempt my questions

27) ... the situation of me having $100 \%$ assurance of my student

28) ... the great love we student have for our dear teachers

29) We can never have bad student but bad teachers.

30) ... teaching practice is a way of training students in higher institution of ...

31) Teaching Practice is to get the minds and soul of the students ready

A close study of the count nouns in 1-31 reveals that either the situational context or syntactic environment or both obligatorily demand pluralisation, but this was not the case. Unlike the other six contexts already examined (which covers all cases of suppliance of the -S plural morpheme in non-obligatory contexts and three of non-suppliance in obligatory contexts), where there was syntactic proximity between the modifier and noun headword, the subset of "other obligatory contexts" is characterised more by syntactic remoteness (if not abstractness as well) than contact with respect to number. The noun headword and the items that make plural marking contextually obligatory were in considerable distance to each other syntactically: They occurred in separate nominal groups that realise different elements of the clause structure or parts thereof as subject and complement. One example is the occurrence of things and student, complement and part of adjunct respectively, in 26. There is moreover what I choose to call situationally understood plural context. This is not immediately visible grammatically, but it nevertheless forms an integral part of each essay's textuality. It is inconceivable that the referent of student in $25-27$ could have been just one learner. These factors explain some of the omissions of the -S plural morpheme in $1-31$ as will be seen shortly, but they do not account for all the errors.

It is not possible to take on all the 31 items in any meaningful detail due to space constraints and this must be acknowledged straight away. However, collective justice can still be done to them. Beginning with 1-4, the participant's knowledge of elections ought to have told them that result sheets and vehicles 
transporting electoral materials cannot be one, that making preparations for a national election can be multi-faceted, and that fire gutting three INEC state offices presupposes there were three (fire) incidents. The failure to supply the -S plural morpheme in these contexts might have an underlying L1 influence. Poor learning, coupled with L1 influence, accounts for 14, 15 and 21, where the sequences "one of" and "among the" require that the noun that follows be plural. Sloppiness largely explains 17-20 because, as the contexts reveal, the plural form was supplied even in connection with the most frequently unmarked student. Cognisance should also be taken of the fact that this participant's two primary languages do not mark plural morphologically. Without running contrary to the decision to not reveal participants' identities, it is useful to point out that only 8 participants were responsible for the 31 errors, each producing 1-4, 5 - 9, 10 $14,15-16,17-20,21,22-29$, and $30-31$ in that order. The earlier statement attributing 74 percent of the 87 errors to 6 participants remains valid.

\section{Discussion}

This is a study of the acquisition and use of the -S plural morpheme by thirdyear students of English in a Nigerian university. It aimed at identifying all accurate and inaccurate instantiations of its usage, determining their frequency of occurrence, specifying the exact syntactic, lexical or semantic context of occurrence of each -S plural morpheme bearing or non-bearing common noun, providing explanations for error incidence among this category of advanced L2 learners, and suggesting ways of improving L2 learners' acquisition and use of the English -S plural morpheme. The data comprised 1219 common nouns derived from a 6103-word corpus of written material produced by 15 volunteer English Education students at the Lagos State University. The combined CA-EAIL theory underpinned the study, which also employed non-morphological categories to account for errors and non-errors alike. This section summarises and discusses the findings and observations made.

Accurate and inaccurate instantiations of the $-S$ plural morpheme respectively represent 93 percent (1132) and 7.14 percent (87) of the 1219 common nouns that constitute the data. Accurate instantiation reflected in the 905 cases of non-suppliance in non-obligatory contexts and 227 incidents of suppliance in obligatory contexts, while inaccurate instantiations featured as 73 (84 percent) cases of non-suppliance of the -S plural in obligatory contexts and 14 (16 percent) of its suppliance in non-obligatory contexts. Errors of misuse (suppliance in non-obligatory contexts) were thus far less than errors of omission (non-suppliance in obligatory contexts), contrary to Akande's (2003) report. Indeed, errors of misuse were 5.3 times more frequent in this study and 4 times less frequent in Akande's. Amer (2009) reported that omission is an error associated with the -S plural morpheme but did not state its frequency relative to misuse. Error mean was 5.8 percent, although the range was between 16 and 1, with only one essay emerging error-free with respect to the $-\mathrm{S}$ plural morpheme. The highest 
percentage of errors by a participant relative to the data was 20 and the lowest was 0.82 .

Admitted that third-year undergraduate students of English unarguably lie outside the category of L2 learners for whom ignorance of plural formation rules would be a tenable excuse for errors, it should nevertheless be acknowledged that awareness of the existence of a rule does not necessarily translate to accuracy of, or consistency in, its application. As this study has shown, a learner may lack awareness of the different syntactic and semantic contexts for obligatory and non-obligatory plural marking despite knowing the rules. This explains why, even in incontestably singular or plural contexts, some participants still failed to act appropriately by inflecting or not inflecting the common noun. One notable culprit is non-contextualisation. This is the pedagogic practice that presents grammatical items in isolation and as discrete items devoid of meaning. The average Nigerian L2 learner encounters 'singular and plural' this way, and struggles to add $-s$ or -es to regular nouns glossed in a table. It is this practice that has continued to militate against the proper acquisition and use of the $-\mathrm{S}$ plural morpheme. Another notable factor identified is over-generalisation of rules, and this is consistent with Jia's (2003) findings. Three other related causes are indiscriminate application of rules, misapplication of rules, and inconsistency in rule application, typified by the concurrent marking and omission of the plural form in two contiguous count nouns.

Although L1 influence was overly implicit, the clearest case was the phonologically-induced orthographical error in which lives was realised as lifes. That only 1.12 percent of incorrect instantiations was directly linked to L1 influence tends to confirm Murukami \& Alexopoulou's (2016) finding that the -S plural morpheme does not show a strong L1 influence. It also proves wrong the assertion repudiated by Oshodi (2014) that missing inflections are a marked feature of Nigerian English (If that were true, there would have been more cases). This finding further justifies the theoretical approach adopted for this study, which made it possible to account for the data at different levels. Poor learning, poor recognition of form, and hyper-correction were also implicated in different degrees. One other factor is the inherent difficulty of the -S plural morpheme as a grammatical form, which includes the fact that the inflected noun is determined by the syntax of the language. These are all very strong factors to be reckoned with in the explanation of error sources and causes in L2 acquisition.

The findings made in this study can be viewed from two broad perspectives, namely occurrence and non-occurrence of errors. That 93 percent of common noun occurrence represent accuracy in usage suggests that majority of L2 learners at the level of third-year university students of English have effectively mastered the plural form. They have learnt its rules and the contexts in which they apply or do not apply. This is in agreement with Bliss' (2006) postulation that it is improved learning that accounts for advanced learners' attainment of higher stages of accuracy and not some imagined activation of a non-existent L1 feature 
as held by proponents of FFFH. Given the participants' academic background, defined by their exposure to superior knowledge not technically available to the average L2 learner, this development is not unexpected.

However, the fact that errors occurred at all tends to both reinforce the view shared by EA proponents that errors are inevitable in L2 acquisition and provide evidence of failure of learning despite exposure to highly technical skills and advanced knowledge. Furthermore, that some errors were directly linked to the users' L1 backgrounds, the small number notwithstanding, attests to the claims by CA theorists that $\mathrm{L} 2$ learners tend to transfer features of their $\mathrm{L} 1$ in the process of learning the new language. It is noteworthy that the same 6 participants who accounted for 74 percent of total error occurrence also committed 81 percent of the non-suppliance-in-obligatory-contexts errors. This shows that some persons will fail to learn a language successfully irrespective of the quality and duration of exposure to the learning content, which is consistent with the views of IL proponents. Even where the -S plural morpheme was correctly supplied in obligatory contexts or appropriately not supplied in non-obligatory contexts, which are proofs of proper acquisition and correct usage respectively, the excerpts are attestations of general poor language usage representing the users' interlanguage grammars. That this study's participants are prospective English teachers is ominous for the future of English language teaching and learning in Nigeria's secondary schools.

\section{Conclusion}

This study's uniqueness lies in its participants and in the methods of analysis adopted. In the study of L2 morpheme acquisition attention has not really been paid to learners studying for a degree in English in order to fully understand precisely what goes on in the acquisition process, be it right or wrong. The third-year undergraduates of English Education that participated in this study prove that greater accuracy can be achieved and sustained by the L2 learner of the -S plural morpheme with longer, wider and deeper exposure to all its relevant facts as a grammatical form. In the same breadth, it proves, ironical as this may seem, that despite the length and depth of exposure, only a limited amount of success can be recorded with learners for whom an interlanguage grammar is a target variety.

The decision to incorporate syntactic and textual sub-levels into the analysis was premised on the firm conviction that, to truthfully explain the acquisition and use of a given grammatical form, a study such as this must examine the form in its total environment. Incorporating these non-morphological aspects particularly made it possible to adequately account for errors and non-errors in ways not previously explored or reckoned with in morpheme studies. It showed that diligent consideration for context of occurrence and context of use is vital to the explanation of accurate and inaccurate usage. In particular, it facilitated the differentiation of errors of suppliance in non-obligatory contexts and errors of 
non-suppliance in obligatory contexts, and provided insights into the syntactic and textual behaviours of the two error types. So, it is now possible to say, for example, that while suppliance errors in non-obligatory contexts occur in the environment of count nouns and mass nouns, errors of non-suppliance in obligatory contexts are associated with elaborated, textually obligatory contexts. It is not known whether syntactic context or textual context or both have played any major roles in previous studies.

Three pertinent questions arise from the fact that this study's participants have had three years of rigorous undergraduate study of English as an academic discipline. These are: What did they learn? How did they get to where they are? What will they teach upon graduation? To answer these questions and forestall a situation where 1 in 5 common nouns in a third-year English undergraduate's essay manifests an error of number, as P2 attests (See Table 1), decisive steps must be taken. First, the current admission policy into the universities should be reviewed to exclude unsuitable candidates who cannot learn. In particular, the Education Faculty must stop accepting intellectual rejects since no nation can rise beyond its teachers. Second, the Course Unit System should be reappraised so that very weak students that cannot benefit from instruction are not retained unduly. Finally, while it is easy to ask that the English degree programmes be reviewed to embrace more grammar, the sad reality is that the few Departments of English with excellent grammar courses lack suitable personnel to handle them. Grammar is generally perceived as difficult and abstract. Consequently, successive generations of doctoral students in this clime avoid it like a plague. To address this fundamental problem, prospective university teachers should be encouraged to undertake research in the core areas of grammar and phonology. It bears repeating what has become for me axiomatic that no one can effectively teach another a language whose description they do not know.

One major limitation of this study is the absence of a spoken data component. The phonological level remains the one area where variations capable of distorting meaning and inhibiting mutual intelligibility in ESL acquisition and use are most greatly pronounced. So, it would certainly be interesting to find out if the same errors that occur in writing also manifest in speech and whether variations exist in the realisation of the -S plural morpheme's three phonologically conditioned allomorphs. These special interests could however not be pursued (even after tape recording five participants) due to serious logistical constraints. This is a challenge for some other day.

\section{Conflicts of Interest}

The author declares no conflicts of interest regarding the publication of this paper.

\section{References}

Adams, V. (1973). An Introduction to English Word-Formation. London: Longman. 
Afolayan, A. (1985). Errors and the Teaching of English. In K. R. Janowsky (Ed.), Scientific and Humanistic Dimensions of Language: Festschrift for Robert Lado on the Occasion of His 70th Birthday on May 31, 1985 (pp. 1-14). Amsterdam: John Benjamins Publishing Co.

Ajiboye, O. (2010). Plural Marking in Yoruba and English and Its Pedagogical Implications. Sintagma, 22, 17-36. https://pascal-francis.inist.fr/vibad/index.php

Akande, A. T. (2003). Acquisition of Inflectional Morphemes by Nigerian Learners of English Language. Nordic Journal of African Studies, 12, 310-326.

http://www.njas.helsinki/fi

Amer, F. H. (2009). Phonological and Morphological Issues in Learners' Performance of English as a Foreign Language. A Case Study of Ninth Grade Students of Tayboh Secondary School for Girls in Malan Governorate, Jordan. Amman, Jordan: Middle East University for Graduate Studies. http://meu.edu.jo/libraryTheses/

Andrew-Ogidi, R. C. (2006). A Comparative Analysis of English and Igala Morphological Processes. Zaria, Nigeria: Ahmadu Bello University.

https://kubanni.abu.edu.ng/jspui/bitstream

Behjat, F., \& Sadighi, F. (2011). The Acquisition of English Grammatical Morphemes: The Case of Iranian EFL Learners. Modern Journal of Applied Linguistics, 3, 105-123. https://www.mjal.org.lib.ed.ac.uk/bistream/handle

Bliss, H. (2006). L2 Acquisition of Inflectional Morphology: Phonological and Morphophonemic Transfer Effects. In M. G. O’Brien, C. Shea, \& J. Archibald (Eds.), Proceedings of the 8th Generative Approaches to Second Language Acquisition Conference (pp. 1-8) Somerville, MA: Cascadilla Proceedings Project. www.lingref.com/cpp/gasla/8/paper

Christophersen, P., \& Sandved, A. O. (1969). An Advanced English Grammar. London: Macmillan.

Feng, L. S. (2012). The Acquisition of Plurals in English Writing by Two Groups of Hong Kong Students. Edinburgh: The University of Edinburgh. https://www.era.lib.ed.ac.uk/

Hawkins, R., \& Chan, C. Y. (1997). The Partial Availability of Universal Grammar in Second Language Acquisition: The Failed Functional Features Hypothesis. Second Language Acquisition, 13, 187-226. https://doi.org/10.1191/026765897671476153

Hazendar, B., \& Schwartz, B. (1997). Are there Optional Infinitives in Child L2 Acquisition? In E. Hughes, M. Hughes, \& A. Greenhill (Eds.), Proceedings of the 21st Annual Boston University Conference on Language Development (pp. 257-268). Somerville, MA: Cascadilla Proceedings Project.

Haznedar, B. (2003). Missing Surface Inflection in Adult and Child L2 Acquisition. In M. Liceras et al. (Eds.), Proceedings of the Generative Approaches to Second Language Acquisition Conference (pp. 140-149). Somerville, MA: Cascadilla Proceedings Project. www.lingref.com/cpp/gasla/paper 1038

Jia, G. (2003). The Acquisition of the English Plural Morpheme by the Native Mandarin Chinese-Speaking Children. Journal of Speech and Hearing Research, 46, 1297-1311. https://doi.org/10.1044/1092-4388(2003/101)

Jing, L., Tindall, E., \& Nisbet, D. (2014). Chinese Learners and English Plural Forms. The Linguistics Journal, 1, 127-147. https://www.linguistics-journal.com/

Kato, A., Adamson, H. D., Uneneka, R., Stauffer, L. A., \& Chu, L. (1999). Interlanguage Variation in the Use of the English Plural Morpheme by Japanese ESL Speakers: A Comparison with Chinese ESL Speakers. Arizona Working Papers in SLAT, 7, 1-15. https://journals.uair.arizona.edu/.index.php/AZSLAT

Lado, R. (1957). Linguistics across Cultures. Ann Arbor, MI: The University of Michigan 
Press.

Lardiere, D. (1998a). Case and Tense in the Fossilized Steady State. Second Language Research, 14, 1-25. https://doi.org/10.1191/026765898674105303

Lardiere, D. (1998b). Dissecting Syntax from Morphology in a Divergent End State Grammar. Second Language Research, 14, 359-375. https://doi.org/10.1191/026765898672500216

Murukami, A., \& Alexopoulou, T. (2016). L1 Influence on the Acquisition of English Grammatical Morphemes: A Learner Corpus. Studies in Second Language Acquisition, 38, 365-401. https://doi.org/10.1017/S0272263115000352

Ninpanit, S., \& Pongpairoj, N. (2016). The Acquisition of the English Plural Morpheme by L1 Thai Learners: A Case of the Failed Functional Features Hypothesis. PASAA Paritat, 31, 53-80. https://www.culi.chula.ac.th/publicationsonline

Nweya, G. O. (2016). Plural Strategies and Devices in Igbo. Kansas Working Papers in Linguistics, 37, 1-22. https://kuscholarworks.ku.edu/handle/1808/23230

Oshodi, B. (2014). Assessing the So-Called Marked Inflection Features of Nigerian English: A Second Language Acquisition Theory Account. Ikala Revista de Lenguaje y Cultura, 19, 15-26.

https://www.aprendeenlinea.udea.edu.eo/revista/index.php/article/view/14303/20783313

Prévost, P., \& White, L (2000). Missing Surface Inflection or Impairment in Second Language Acquisition: Evidence from Tense and Agreement. Second Language Acquisition, 15, 133-166. https://doi.org/10.1191/026765800677556046

Quirk, R., Greenbaum, S., Leech, G., \& Svartvik, J. (1985). A Comprehensive Grammar of the English Language. London: Longman.

Richards, J. C. (1974). A Non-Contrastive Approach to Error Analysis. In Error Analysis: Perspectives on Second Language Acquisition (pp.172-188). London: Longman.

Selinker, L. (1974). Interlaguage. In J. C. Richards (Ed.), Error Analysis: Perspectives on Second Language Acquisition (pp.37-54). London: Longman.

Strang, B. (1969). Modern English Structure. London: Edward Arnold. 